\title{
Efficacy and safety of multiple doses of levomilnacipran extended-release for the treatment of major depressive disorder
}

This article was published in the following Dove Press journal:

Neuropsychiatric Disease and Treatment

25 October 2016

Number of times this article has been viewed

\section{Qunlian Huang' \\ Xiaoyan Zhong' \\ Ye Yun' \\ Bin $Y^{2}$ \\ Yilan Huang'}

'Department of Pharmacy, The Affiliated Hospital of Southwest Medical University, ${ }^{2}$ Department of Clinical Pharmacy, School of Pharmacy, Southwest Medical University, Luzhou, Sichuan Province, People's Republic of China
Correspondence: Yilan Huang Department of Pharmacy, The Affiliated Hospital of Southwest Medical University, No 25 Taiping Street, Luzhou 646000 , Sichuan Province, People's Republic of China

Tel +86 18982423710

Fax +86 08303165787

Email hyl3160131@I63.com
Objective: The aim of this meta-analysis was to evaluate the efficacy and safety of levomilnacipran extended-release (ER) in the treatment of major depressive disorder (MDD).

Methods: Randomized controlled trials were searched by electronic databases. Unpublished data were also searched by the relevant websites. Weighted mean difference (WMD) and risk ratio (RR) with $95 \%$ confidence interval (CI) were calculated and pooled using fixed-effects model or random-effects model.

Results: Five randomized placebo-controlled trials including 2,637 patients were analyzed. Compared with placebo, levomilnacipran ER had a greater reduction in the MontgomeryÅsberg Depression Rating Scale (MADRS) total score and Sheehan Disability Scale (SDS) total score (MADRS: WMD -3.49 [95\% CI -4.28, -2.70; $P<0.00001]$; SDS: WMD -2.41 [95\% CI $-3.05,-1.77 ; P<0.00001])$. Significantly more patients in levomilnacipran ER achieved MADRS response rate (RR 1.35 [95\% CI 1.23, 1.47; $P<0.00001])$ and MADRS remission rate (RR 1.30 [95\% CI 1.06, 1.59; $P=0.01]$ ). In terms of safety, more patients discontinued due to adverse events (AEs) in levomilnacipran ER compared with placebo (RR 3.15 [95\% CI 2.26, 4.39; $P<0.00001]$ ), but it was generally well tolerated in each eligible trial. The most common AEs were nausea, delay in ejaculation, erectile dysfunction, tachycardia, headache and increase in heart rate.

Conclusion: Levomilnacipran ER is a safe and effective short-term treatment for MDD ( $\leq 10$ weeks). Long-term and head-to-head trials comparing levomilnacipran ER with other antidepressants are needed to confirm the conclusion.

Keywords: levomilnacipran ER, SNRI, major depressive disorder, meta-analysis

\section{Introduction}

Major depressive disorder (MDD) is one of the most prevalent mental disorder and is estimated to be the fourth leading cause of disease burden worldwide. ${ }^{1,2}$ Pharmacotherapy is the primary choice for MDD. However, most antidepressants lacked efficacy and tolerability for patients with MDD, and adverse effects were the leading reasons of discontinuation during the treatment. ${ }^{3,4}$ Therefore, new antidepressants that can offer a greater advantage in efficacy and tolerability are needed. In this regard, levomilnacipran, which has a unique pharmacological activity compared with currently marketed serotonin-norepinephrine reuptake inhibitors (SNRIs), may prove to be an appealing alternative.

Levomilnacipran (1S, 2R-milnacipran) extended-release (ER), as the fourth SNRI, was approved by the US Food and Drug Administration (FDA) in July 2013 with doses of 40-120 mg capsule once daily. ${ }^{5}$ In vitro studies have shown that levomilnacipran 
ER has twofold greater potency for norepinephrine compared with serotonin reuptake inhibition. ${ }^{6}$ Compared with duloxetine, desvenlafaxine, or venlafaxine, levomilnacipran ER showed 10-fold greater selectivity for inhibiting norepinephrine reuptake. ${ }^{7}$

The efficacy and safety of levomilnacipran ER have been evaluated in several clinical studies, but the evaluation results were not completely consistent. A recent review had pooled the efficacy of levomilnacipran ER for MDD, using Cohen's $d$ and number-needed-to-treat (NNT) as effect sizes, ${ }^{8}$ which did not evaluate the safety of levomilnacipran ER and the effect on Sheehan Disability Scale (SDS). However, a significant improvement in SDS may demonstrate efficacy in treating functional impairment. ${ }^{9}$ Thus, the aims of this article were to systematically review the existing published data regarding the treatment of MDD comparing levomilnacipran ER and placebo (including Montgomery-Åsberg Depression Rating Scale [MADRS] total score, SDS total score, response rate, remission rate, adverse effects, and cardiovascular effects) and to evaluate the efficacy and safety of levomilnacipran ER.

\section{Methods}

\section{Data sources and search strategy}

We searched PubMed, Embase, Medline, Ovid, the Cochrane Collaboration Library, Scopus and ScienceDirect, PsycInfo, and International Pharmaceutical Abstracts from inception to March 2016, without restriction of language. Potentially relevant unpublished data were searched by ClinicalTrials.gov, FDA website, European Union Drug Regulating Authorities Clinical Trials and the World Health Organization International Clinical Trials Registry Platform. We used the following terms: "levomilnacipran", "LVM", "fetzlma", "F2695", "major depressive disorder", "depression or major depression", and "MDD". These terms were adjusted to comply with the relevant rules in each database.

\section{Study election}

Two investigators ( $\mathrm{QH}$ and $\mathrm{XZ}$ ) independently reviewed the title and abstract and selected randomized controlled trials of levomilnacipran ER for the treatment of MDD. All the studies met the following criteria:

1. All patients (18-80 years of age) were diagnosed for MDD by the Diagnostic and Statistical Manual of Mental Disorder, fourth edition, text revision and confirmed by the Mini International Neuropsychiatric Interview.

2. All patients were required to have baseline MADRS total score $\geq 26$.
3. MADRS total score was used as the primary outcome in eligible studies.

4. Studies included one or more of the secondary outcomes: SDS total score, MADRS remission rate (total score $\leq 10)$, MADRS response rate ( $\geq 50 \%$ improvement from baseline), adverse events (AEs), and cardiovascular effects.

Full-text articles were retrieved independently by two investigators ( $\mathrm{QH}$ and $\mathrm{XZ})$. If they had a disagreement, the third investigator ( $\mathrm{YH}$ ) was used to solve the disagreement when necessary.

\section{Data extraction}

Data were extracted by two investigators (QH and XZ), and any discrepancies were resolved by consensus. For each study, two investigators (QH and XZ) extracted information on study characteristics, participants' baseline characteristics, interventions of the trial, end points, and findings.

\section{Quality assessment}

Two investigators $(\mathrm{QH}$ and $\mathrm{XZ})$ assessed the quality of included studies by using the risk of bias tool. ${ }^{10}$ The predefined key domains included random sequence generation, allocation concealment, blinding, and other items (ie, efficacy analysis, lost to follow-up, intention-to-treat analysis, and statistical analysis).

\section{Statistical analysis}

All outcomes were pooled by using RevMan 5.3 software (Nordiac Cochrane Center, Copenhagen, Denmark; http:// www.cochrane.org/). For dichotomous data, risk ratio (RR) was calculated with $95 \%$ confidence intervals (CIs). On the other hand, in case of continuous data, we used weighted mean difference (WMD) with $95 \%$ CIs. We calculated the $I^{2}$ statistic to estimate heterogeneity. If $I^{2}$ was $<50 \%$, we chose fixed-effect model with the analyses of the Mantel-Haenszel method; otherwise, the random-effect model was adopted.

\section{Results}

\section{Literature search and study characteristics}

A total of 859 records were identified by our initial search. According to title and abstract, we excluded 825 records (irrelevant, annual meeting, animal, duplicates). Finally, we excluded 29 records and confirmed five studies that met the inclusion criteria by two investigators screening full-text articles. The flow of study search and selection is shown in Figure 1. 


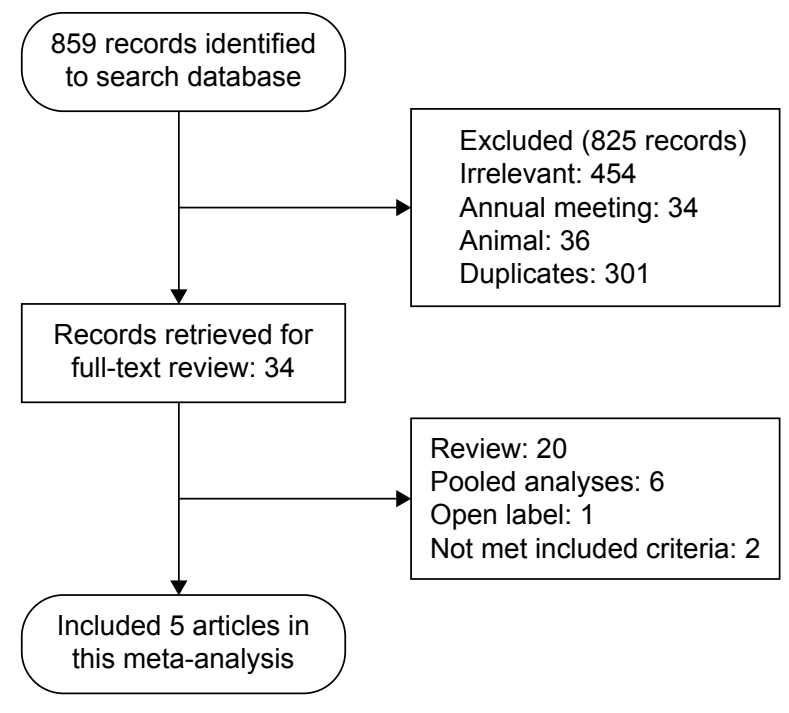

Figure I The flow of the study search and selection.

Five studies were randomized, double-blind, placebocontrolled trials. These included two fixed-dose trials ${ }^{11,12}$ and three flexible-dose trials. ${ }^{13-15}$ Trial durations ranged from 8 to 10 weeks. A total of 2,637 patients were randomized to the levomilnacipran ER group and placebo group, 2,623 patients were used for safety analyses and 2,598 patients were used for modified intent-to-treat and efficacy analyses (1,032 were randomized to placebo and 1,566 to the levomilnacipran ER group). The basic characteristics of the study are listed in Table 1.

\section{Quality assessment}

All eligible studies described the generation of the randomization sequence. However, allocation concealment was unclear in one study. ${ }^{14}$ All studies were at least double blind.
Five studies reported adequate intention-to-treat analysis. ${ }^{11-15}$ Loss to follow-up was minimal and balanced in the five trials. Details of risk of bias assessment are shown in Table 2.

\section{MADRS total score}

Compared with placebo, a statistically significant reduction in the MADRS total score was observed in the levomilnacipran ER group (WMD -3.49 [95\% CI -4.28, -2.70; $P<0.00001]$; Figure 2). The subgroup analysis results were WMD -3.26 (95\% CI $-4.95,-1.57 ; P=0.0002)$ for $40 \mathrm{mg}$, WMD -3.45 (95\% CI $-5.14,-1.75 ; P<0.0001)$ for $80 \mathrm{mg}$, WMD $-4.90(95 \% \mathrm{CI}-7.66,-2.14 ; P=0.0005)$ for $120 \mathrm{mg}$, and WMD -3.37 (95\% CI $-4.50,-2.24 ; P<0.00001)$ for 40-120 mg (Figure 2).

In a sensitivity analysis, pooling the data on MADRS showed that the overall estimate was not impacted by excluding a phase II study ${ }^{15}$ (WMD -3.24 [95\% CI -4.16, -2.33; $P<0.00001])$.

\section{SDS total score}

The pooled effects estimate of the SDS total score was -2.41 (95\% CI $-3.05,-1.77 ; P<0.00001)$. The results of the subgroup analysis also demonstrated that levomilnacipran ER was superior to placebo on the SDS total score (40 mg: WMD -1.68 [95\% CI $-3.06,-0.30 ; P=0.02], 80 \mathrm{mg}: \mathrm{WMD}-2.67$ [95\% CI $-4.05,-1.29 ; P=0.0001], 120 \mathrm{mg}:$ WMD -2.5 [95\% CI $-4.61,-0.39 ; P=0.02]$, and $40-120 \mathrm{mg}$ : WMD -2.35 [95\% CI $-3.88,-0.82 ; P=0.003]$; Figure 3).

\section{Response rate and remission rate}

Levomilnacipran ER had a greater improvement in the MADRS response rate compared with placebo (40 $\mathrm{mg}$ : RR

Table I The basic characteristics of randomized controlled trials (mean \pm SD)

\begin{tabular}{|c|c|c|c|c|c|c|}
\hline Study & $\begin{array}{l}\text { Duration of } \\
\text { intervention (wk) }\end{array}$ & Interventions (n) & Age (years) & Weight (kg) & $\begin{array}{l}\text { Baseline } \\
\text { MADRS score }\end{array}$ & Outcomes \\
\hline \multirow[t]{4}{*}{ Asnis et al' } & 8 & LVM 40 mg/d (I 78) & $41.6 \pm 13.1$ & $79.5 \pm 17.1$ & $35.6 \pm 4.5$ & MADRS, SDS: \\
\hline & & LVM 80 mg/d (I79) & $41.0 \pm 12.8$ & $83.0 \pm 17.3$ & $36.0 \pm 4.1$ & response, remission \\
\hline & & LVM 120 mg/d (I80) & $40.3 \pm 11.9$ & $84.2 \pm 18.6$ & $36.1 \pm 3.9$ & \\
\hline & & Placebo (I76) & $41.3 \pm 11.3$ & $83.8 \pm 19.3$ & $36.0 \pm 3.9$ & \\
\hline \multirow[t]{3}{*}{ Bakish et $\mathrm{al}^{12}$} & 8 & LVM 40 mg/d (I88) & $42.9 \pm 13.4$ & $81.3 \pm 17.0$ & $30.8 \pm 3.4$ & MADRS, SDS: \\
\hline & & LVM 80 mg/d (I88) & $43.1 \pm 12.8$ & $81.7 \pm 17.5$ & $31.2 \pm 3.5$ & response, remission \\
\hline & & Placebo (186) & $42.3 \pm 13.2$ & $81.6 \pm 17.7$ & $31.0 \pm 3.8$ & \\
\hline \multirow[t]{2}{*}{ Gommoll et $\mathrm{al}^{13}$} & 8 & LVM flexible dose (I75) & $42.8 \pm 12.9$ & $82.4 \pm 18.1$ & $35.9 \pm 4.1$ & MADRS, SDS: \\
\hline & & Placebo (I82) & $43.7 \pm 13.3$ & $82.9 \pm 18.0$ & $35.5 \pm 4.0$ & response, remission \\
\hline \multirow[t]{2}{*}{ Sambunaris et $\mathrm{al}^{14}$} & 8 & LVM flexible dose (222) & $45.0 \pm 13.2$ & $84.4 \pm 18.9$ & $35.0 \pm 3.6$ & MADRS, SDS: \\
\hline & & Placebo $(220)$ & $44.6 \pm 13.9$ & $84.5 \pm 18.1$ & $35.2 \pm 3.8$ & response, remission \\
\hline \multirow[t]{2}{*}{ Montgomery et $\mathrm{al}^{15}$} & 10 & LVM flexible dose (282) & 45 & $N / R$ & $30.9 \pm 4.1$ & MADRS, SDS: \\
\hline & & Placebo $(28 I)$ & 44 & $N / R$ & $30.5 \pm 3.7$ & response, remission \\
\hline
\end{tabular}

Abbreviations: wk, week; MADRS, Montgomery-Åsberg Depression Rating Scale; LVM, levomilnacipran; d, day; SDS, Sheehan Disability Scale; N/R, not reported; SD, standard deviation. 
Table 2 Risk of bias assessment

\begin{tabular}{|c|c|c|c|c|c|c|c|}
\hline Study & $\begin{array}{l}\text { Random sequence } \\
\text { generation }\end{array}$ & $\begin{array}{l}\text { Allocation } \\
\text { concealment }\end{array}$ & Blinding & $\begin{array}{l}\text { Efficacy } \\
\text { analysis }\end{array}$ & $\begin{array}{l}\text { Lost to } \\
\text { follow-up }\end{array}$ & ITT & $\begin{array}{l}\text { Statistical } \\
\text { analysis }\end{array}$ \\
\hline Asnis et al"I & $\mathrm{Y}$ & $Y$ & Y & MMRM & $Y$ & $Y$ & ANCOVA \\
\hline Bakish et al' ${ }^{12}$ & $\mathrm{Y}$ & Y & Y & MMRM & $Y$ & $Y$ & ANCOVA \\
\hline Gommoll et $\mathrm{al}^{13}$ & $Y$ & $Y$ & Y & MMRM & $Y$ & $Y$ & ANCOVA \\
\hline Sambunaris et $\mathrm{al}^{14}$ & $Y$ & $u$ & $Y$ & FAS & $Y$ & $\mathrm{~N}$ & ANCOVA \\
\hline Montgomery et $\mathrm{al}^{15}$ & $Y$ & $Y$ & $Y$ & MMRM & $Y$ & $Y$ & ANCOVA \\
\hline
\end{tabular}

Abbreviations: ITT, intention to treat; Y, yes; MMRM, mixed-model for repeated measures; ANCOVA, analysis of covariance; U, unclear; FAS, full analysis set; N, no.

$1.36[95 \%$ CI $1.12,1.64 ; P=0.002], 80 \mathrm{mg}: \mathrm{RR} 1.34[95 \%$ CI 1.10, 1.62; $P=0.003$ ], 120 mg: RR 1.42 [95\% CI 1.06, 1.90; $P=0.02$ ], and 40-120 mg: RR 1.33 [95\% CI 1.17, 1.51; $P<0.0001])$. The overall RR was 1.35 (95\% CI 1.23, 1.47; $P<0.00001$; Figure 4).

The overall RR for the MADRS remission rate was 1.30 (95\% CI 1.06, 1.59; $P=0.01)$. The subgroup analysis results were RR 1.38 (95\% CI $0.91,2.10 ; P=0.12)$ for $40 \mathrm{mg}$, RR 1.40 (95\% CI 0.85, 2.32; $P=0.19)$ for $80 \mathrm{mg}$, RR 1.05 (95\% CI $0.69,1.60 ; P=0.81)$ for $120 \mathrm{mg}$, and RR $1.24(95 \%$ CI $0.81,1.91 ; P=0.31$; Figure 5 ) for $40-120 \mathrm{mg}$.

\section{Safety and tolerability}

Compared with placebo, the overall rate of discontinuation and discontinuation due to AEs was higher for levomilnacipran
ER (Table 3). Incidences of AEs (erectile dysfunction, delay in ejaculation, tachycardia, nausea, hedache, dry mouth, increase in heart rate) were higher for levomilnacipran ER (Table 3). The incidences of suicidal ideation and suicidal behavior were similar between the two groups (Table 3).

Compared with placebo, levomilnacipran ER showed greater increase in the pulse rate (WMD 7.56 [95\% CI 6.81, 8.31; $P<0.00001]$ ), systolic blood pressure (WMD 3.14 [95\% CI 2.37, 3.90; $P<0.00001]$ ), diastolic blood pressure (WMD 3.45 [95\% CI 2.86, 4.05; $P<0.00001]$ ), and Bazett formula (QTcB; Table 4). In the five eligible studies, based on the Fridericia correction (QTcF), there was no QTc prolongation. None of the patients met potentially clinically significant criteria for PR ( $\geq 250$ milliseconds), QTcB (>500 milliseconds), or QTcF ( $>500$ milliseconds) interval.

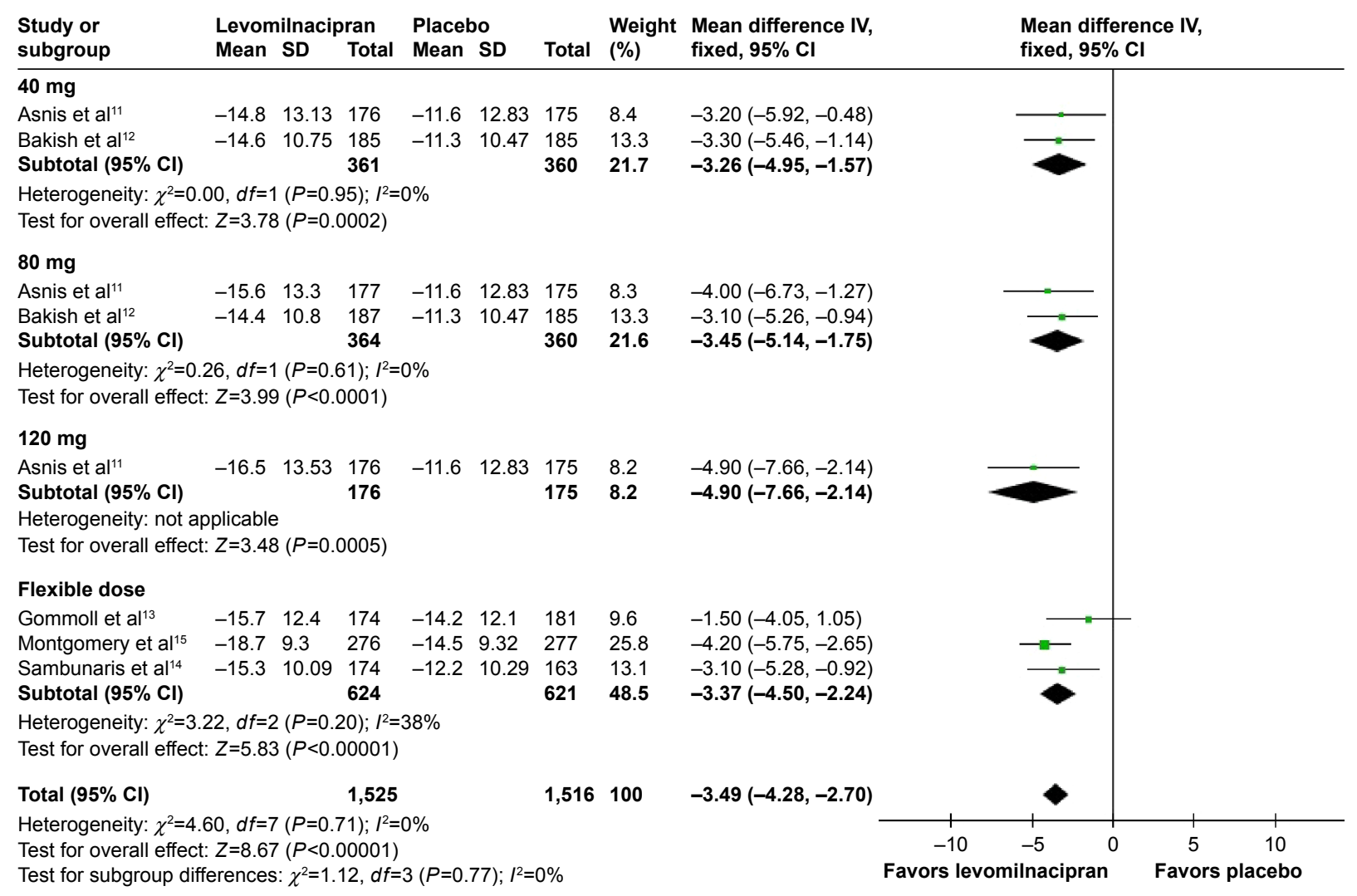

Figure 2 Meta-analysis for change in the MADRS total score from baseline, levomilnacipran ER versus placebo.

Abbreviations: MADRS, Montgomery-Åsberg Depression Rating Scale; ER, extended-release; IV, inverse variance; Cl, confidence interval; SD, standard deviation. 


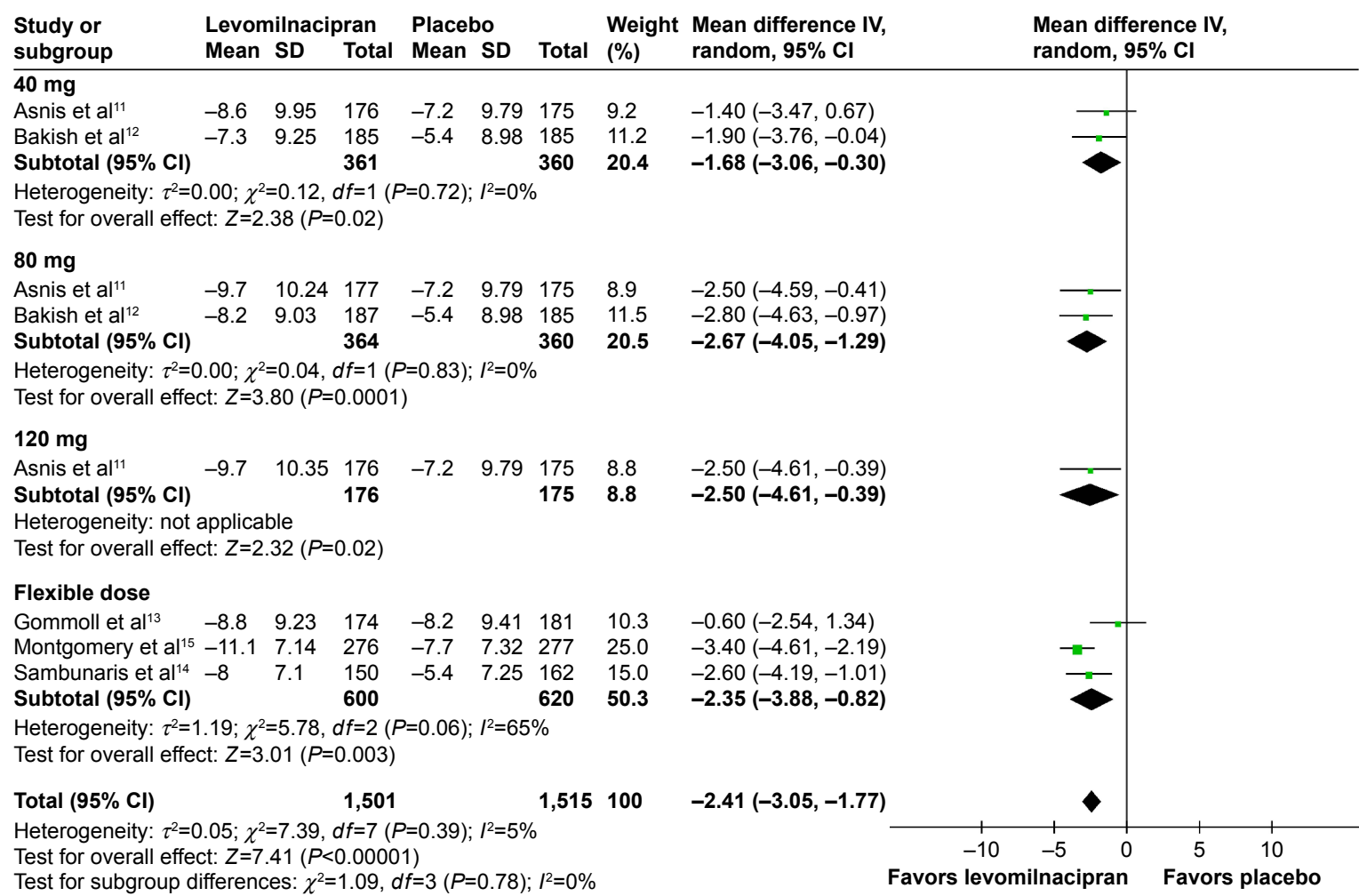

Figure 3 Meta-analysis for change in the SDS total score from baseline, levomilnacipran ER versus placebo.

Abbreviations: SDS, Sheehan Disability Scale; ER, extended-release; IV, inverse variance; Cl, confidence interval.

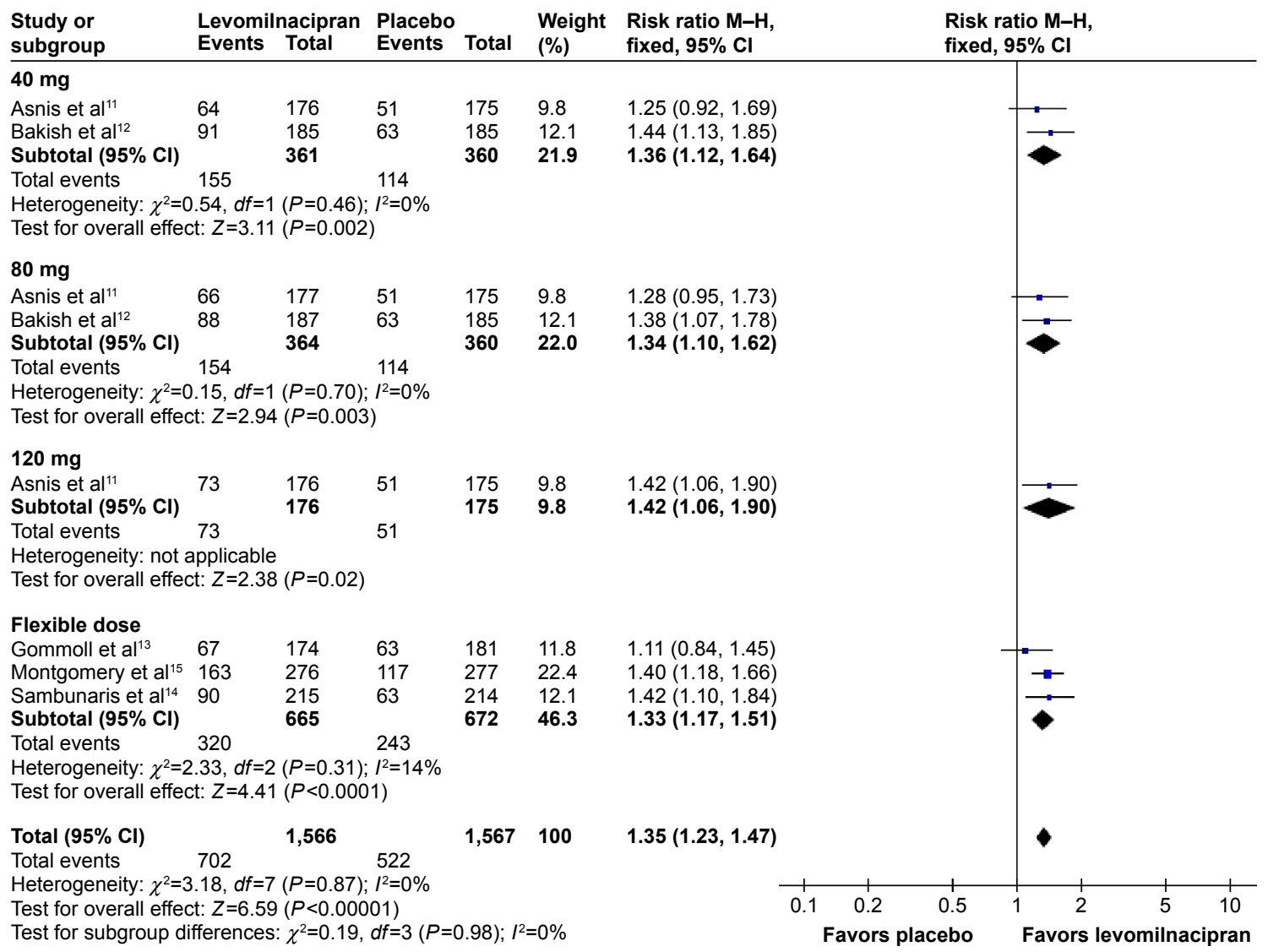

Figure 4 Meta-analysis for MADRS response rate ( $\geq 50 \%$ improvement from baseline), levomilnacipran ER versus placebo.

Abbreviations: MADRS, Montgomery-Åsberg Depression Rating Scale; ER, extended-release; M-H, Mantel-Haenszel; Cl, confidence interval. 


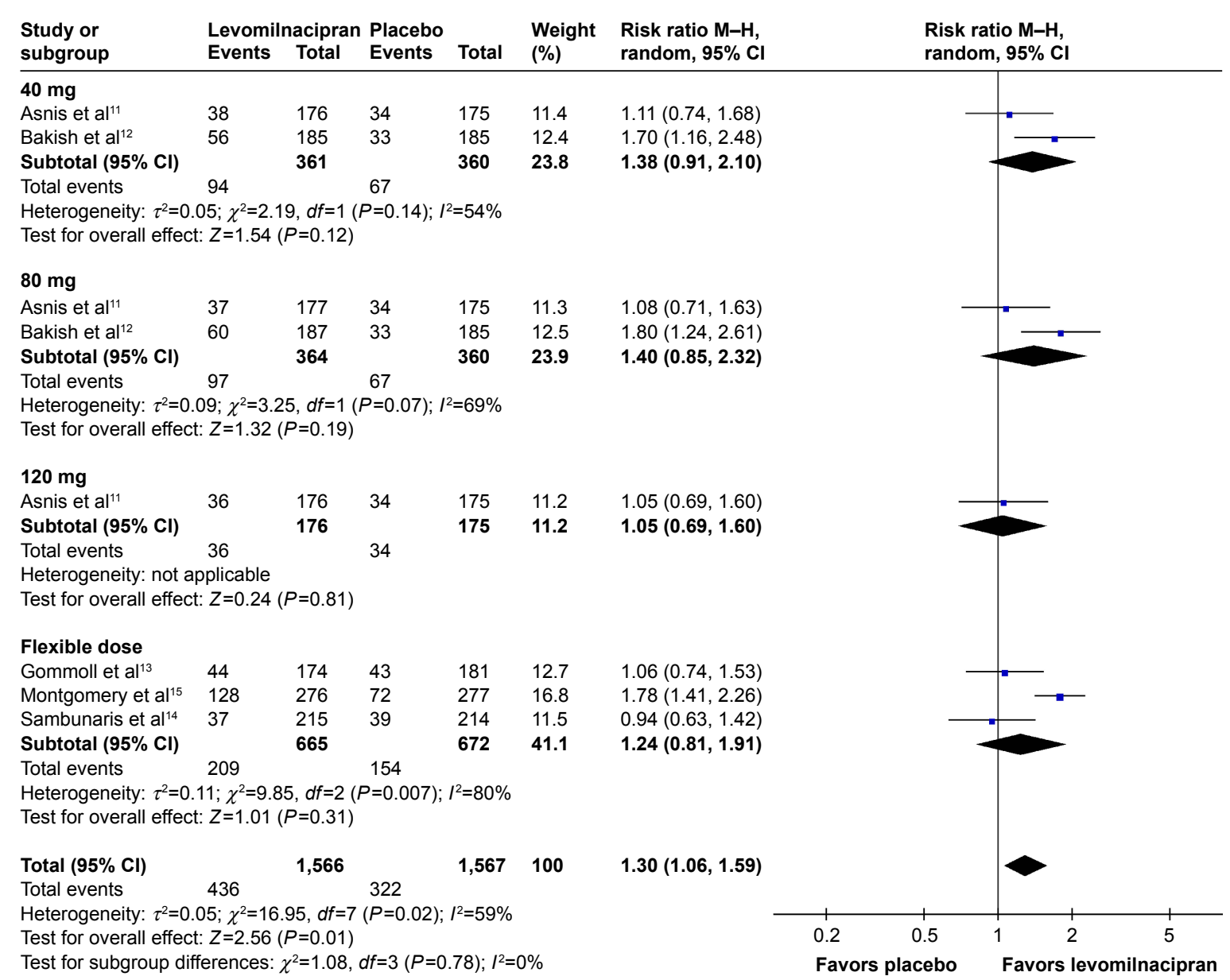

Figure 5 Meta-analysis for MADRS remission rate (total score $\leq 10$ ), levomilnacipran ER versus placebo.

Abbreviations: MADRS, Montgomery-Åsberg Depression Rating Scale; ER, extended-release; $\mathrm{M}-\mathrm{H}, \mathrm{Mantel}-\mathrm{Haenszel}$; Cl, confidence interval.

\section{Discussion}

In our systematic review and meta-analysis, levomilnacipran ER resulted in reduction in the MADRS total score and SDS total score compared with placebo. Levomilnacipran ER has a unique pharmacological activity and is relatively more selective for norepinephrine reuptake inhibition than serotonin reuptake inhibition. ${ }^{6}$ The strong noradrenergic component of antidepressant may be especially effective in improving symptoms related to functioning. ${ }^{16,17}$ Symptomatic and functional improvements are both critical components

Table 3 Meta-analysis for the safety outcomes (dichotomous data)

\begin{tabular}{|c|c|c|c|c|c|}
\hline Outcome & $\begin{array}{l}\text { Levomilnacipran } \\
(\mathrm{n} / \mathrm{N})\end{array}$ & $\begin{array}{l}\text { Placebo } \\
(\mathrm{n} / \mathrm{N})\end{array}$ & $\begin{array}{l}\text { Effect estimate } \\
(95 \% \mathrm{Cl})\end{array}$ & $I^{2}(\%)$ & $P$-value \\
\hline Discontinuation due to all reasons $s^{a}$ & $405 / 1,583$ & $324 / 1,040$ & $1.24(1.09,1.42)$ & 42 & 0.008 \\
\hline Discontinuation due to $\mathrm{AE}$ & $139 / 1,583$ & $44 / 1,040$ & $3.15(2.26,4.39)$ & 41 & $<0.0000$ \\
\hline Erectile dysfunction ${ }^{\mathrm{b}}$ & $29 / 406$ & $9 / 204$ & $3.26(1.56,6.81)$ & 0 & 0.002 \\
\hline Ejaculation delayed ${ }^{\mathrm{b}}$ & $16 / 35 \mid$ & $0 / 208$ & $10.96(2.09,57.56)$ & 0 & 0.005 \\
\hline Tachycardia & $74 / 1,408$ & $15 / 858$ & $3.12(1.50,6.47)$ & 43 & 0.002 \\
\hline Nausea & $272 / 1,583$ & $60 / 1,040$ & $3.80(2.47,5.83)$ & 62 & $<0.0000$ \\
\hline Headache & $262 / 1,583$ & $136 / 1,040$ & $1.40(1.18,1.66)$ & 0 & 0.0001 \\
\hline Dry mouth & $160 / 1,583$ & $73 / 1,040$ & $\mathrm{I} .40(\mathrm{I} . \mathrm{II}, \mathrm{I} .76)$ & 25 & 0.004 \\
\hline Insomnia & $67 / /, 207$ & $4 I / 854$ & $1.22(0.86,1.73)$ & 0 & 0.26 \\
\hline Heart rate increase & $98 / 1,088$ & $13 / 544$ & $0.06(0.04,0.09)$ & 33 & $<0.0000$ \\
\hline Suicidal ideation & $316 / 1,573$ & $172 / 1,037$ & $1.03(0.89,1.19)$ & 9 & 0.72 \\
\hline Suicidal behavior & $5 / 573$ & $1 / 390$ & $2.17(0.49,9.62)$ & 0 & 0.31 \\
\hline
\end{tabular}

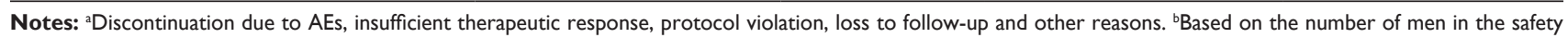
population. Bold numbers are considered statistically significant.

Abbreviations: $\mathrm{Cl}$, confidence interval; $\mathrm{AE}$, adverse event. 
Table 4 Meta-analysis for the safety outcomes (continuous data)

\begin{tabular}{|c|c|c|c|c|c|c|}
\hline \multirow[t]{2}{*}{ Outcome } & \multirow[t]{2}{*}{ Studies (n) } & \multicolumn{2}{|c|}{ Participants analyzed (n) } & \multirow[t]{2}{*}{ WMD $(95 \% \mathrm{Cl})$} & \multirow[t]{2}{*}{$I^{2}(\%)$} & \multirow[t]{2}{*}{$P$-value } \\
\hline & & Levomilnacipran & Placebo & & & \\
\hline Pulse rate & 4 & $\mathrm{I}, 298$ & 756 & $7.56(6.8 I, 8.3 I)$ & 20 & $<0.00001$ \\
\hline SBP & 4 & $\mathrm{I}, 300$ & 756 & $3.14(2.37,3.90)$ & 0 & $<0.00001$ \\
\hline DPB & 4 & 1,300 & 756 & $3.45(2.86,4.05)$ & 0 & $<0.00001$ \\
\hline QTcB & 3 & $|| 7 \mid$, & 631 & $8.59(6.97,10.20)$ & 0 & $<0.00001$ \\
\hline
\end{tabular}

Abbreviations: WMD, weighted mean difference; $\mathrm{Cl}$, confidence interval; SBP, systolic blood pressure; DPB, diastolic blood pressure.

of recovery from MDD. Symptomatic improvement may provide an early sign of treatment response, and functional improvement may be a better indicator of meaningful change. ${ }^{18}$ The MADRS total score $>2$ points for the test group versus placebo, which suggests that symptomatic improvement is clinically relevant. ${ }^{19}$ A significant improvement in SDS means that function is improved. ${ }^{9}$ In our study, the MADRS score exceeded 3.36 points for levomilnacipran ER compared with placebo. In addition, a significant difference in favor of levomilnacipran ER was also observed in the SDS total score. These observations may indicate that levomilnacipran ER might provide both symptomatic and functional efficacies.

If the response rate far exceeds the $10 \%$ average advantage for drug versus placebo, it is generally regarded as sufficient to establish antidepressant treatment advantage. ${ }^{20}$ In our results, the rate of MADRS response was significantly greater for levomilnacipran ER versus placebo.

Most likely due to levomilnacipran ER related to the twofold greater potency for norepinephrine reuptake inhibition compared with serotonin reuptake inhibition, ${ }^{6}$ levomilnacipran ER was generally well tolerated in the five eligible studies, which was consistent with the results of 48-week open-label study and the 39-week relapse prevention study. ${ }^{21,22}$ However, compared with placebo, most incidences of AEs were higher for levomilnacipran ER. The five eligible studies showed that the common AEs were nausea, delay in ejaculation, erectile dysfunction, tachycardia, headache, and increase in heart rate. Pulse rate and blood pressure increases were greater for levomilnacipran ER versus placebo. Greater increase in QTcB was observed in the levomilnacipran ER group compared with placebo, which was consistent with increases in heart rate. The mean QTcF changes were small in both groups. In suicidal ideation and suicidal behavior, levomilnacipran ER and placebo patients had similar numbers.

Milnacipran was approved for the management of fibromyalgia in the US and for the treatment of MDD in many countries outside the US. ${ }^{23,24}$ A earlier systematic review had shown that there was no difference in the overall effectiveness and tolerability between milnacipran and other antidepressants (selective serotonin reuptake inhibitors [SSRIs], tricyclic antidepressants [TCAs]). Additionally, it has some advantages over TCAs in terms of discontinuation due to AEs and the rates of AEs. ${ }^{25}$ Levomilnacipran is the levo enantiomer of milnacipran. Regulatory guidelines in the US and Europe recommend development of the enantiomers over racemates where appropriate. ${ }^{26}$ Given the favorable pharmacokinetic and pharmacodynamic characteristics of enantiomeric formulation, levomilnacipran ER may be more effective than milnacipran. However, head-to-head trials with levomilnacipran ER and milnacipran have not been performed.

\section{Limitations}

There were also limitations in this meta-analysis. First, our analysis highlighted the overall short-term safety and efficacy of levomilnacipran ER; the extended period is needed to understand the long-term benefits and risks. Second, agomelatine is another novel antidepressant that does not induce 5-HT2A stimulation, having a more favorable adverse-effect profile compared with the common SSRIs. ${ }^{27}$ However, the lack of head-to-head trials limited the ability to compare levomilnacipran ER with agomelatine or other antidepressants. Future studies will be needed to compare levomilnacipran ER with other antidepressants. Third, strict inclusion and exclusion criteria might have limited these findings to a smaller population. Future larger studies designed to evaluate patients with recurrent or treatment-resistant depression are necessary. Fourth, levomilnacipran ER appears to display greater noradrenergic activity at a lower dose and increasing effects on serotonergic neurotransmission as the dose increases. ${ }^{28}$ However, our study did not detect doseresponse effects, since most of the clinical studies used flexible dosing.

\section{Conclusion}

This meta-analysis indicated that levomilnacipran ER might be safe and effective for short-term treatment of MDD. However, large, multicenter, randomized controlled trials 
are still needed to assess the safety and efficacy of levomilnacipran ER. Furthermore, head-to-head trials comparing levomilnacipran ER with other antidepressants are needed to confirm the conclusion.

\section{Disclosure}

The authors report no conflicts of interest in this work.

\section{References}

1. Ustün TB, Ayuso-Mateos JL, Chatterji S, Mathers C, Murray CJ. Global burden of depressive disorders in the year 2000. Br J Psychiatry. 2004; 184(5):386-392.

2. Tsuang MT, Taylor L, Faraone SV. An overview of the genetics of psychotic mood disorders. J Psychiatr Res. 2004;38(1):3-15.

3. Fava M. Diagnosis and definition of treatment-resistant depression. Biol Psychiatry. 2003;53(8):649-659.

4. Demyttenaere K, Enzlin P, Dewe W, et al. Compliance with antidepressants in a primary care setting, 1: beyond lack of efficacy and adverse events. J Clin Psychiatry. 2001;62(suppl 22):30-33.

5. Food and Drug administration. US Food and Drug Administration Letter of New Drug Application Approval for Levomilnacipran Extended-Release Capsules (NDA204168); 2013. Available from: www.accessdata.fda.gov/drugsatfda_docs/appletter/2013/204168Ori g1s0001tr.pdf. Accessed November 27, 2013.

6. Auclair AL, Martel JC, Assie MB, et al. Levomilnacipran (F2695), a norepinephrine-preferring SNRI: profile in vitro and in models of depression and anxiety. Neuropharmacology. 2013;70(5):338-347.

7. Deecher DC, Beyer CE, Johnston G, et al. Desvenlafaxine succinate: a new serotonin and norepinephrine reuptake inhibitor. $J$ Pharmacol Exp Ther. 2006;318(2):657-665.

8. Montgomery SA, Gommoll CP, Chen C, Greenberg WM. Efficacy of levomilnacipran extended-release in major depressive disorder: pooled analysis of 5 double-blind, placebo-controlled trials. CNS Spectr. 2015;20(2):148-156.

9. Hirschfeld RM, Montgomery SA, Keller MB, et al. Social functioning in depression: a review. J Clin Psychiatry. 2009;61(4):268-275.

10. Lundh A, Gotzsche PC. Recommendations by Cochrane Review Groups for assessment of the risk of bias in studies. BMC Med Res Methodol. 2008;8(3):57.

11. Asnis GM, Bose A, Gommoll CP, Chen C, Greenberg WM. The efficacy and safety of levomilnacipran sustained release $40 \mathrm{mg}, 80 \mathrm{mg}$, or $120 \mathrm{mg}$ in major depressive disorder: a phase 3, randomized, double-blind, placebo-controlled study. J Clin Psychiatry. 2013;74(3):242-248.

12. Bakish D, Bose A, Gommoll C, et al. Levomilnacipran ER $40 \mathrm{mg}$ and $80 \mathrm{mg}$ in patients with major depressive disorder: a phase III, randomized, double-blind, fixed-dose, placebo-controlled study. J Psychiatry Neurosci. 2014;39(1):40-49.

13. Gommoll C, Greenberg WM, Chen C, et al. A randomized doubleblind, placebo-controlled, study of flexible doses of levomilnacipran ER (40-120 mg/day) in patients with major depressive disorder. J Drug Assess. 2014;3(1):10-19.
14. Sambunaris A, Bose A, Gommoll CP, Chen C, Greenberg WM, Sheehan DV. A phase III, double-blind, placebo-controlled, flexibledose study of levomilnacipran extended-release in patients with major depressive disorder. J Clin Psychopharmacol. 2014;34(1):47-56.

15. Montgomery SA, Mansuy L, Ruth A, Bose A, Li H, Li D. Efficacy and safety of levomilnacipran sustained release in moderate to severe major depressive disorder: a randomized, double-blind, placebo-controlled, proof-of-concept study. J Clin Psychiatry. 2013;74(4):363-369.

16. Kasper $\mathrm{S}$, Meshkat D, Kutzelnigg A. Improvement of the noradrenergic symptom cluster following treatment with milnacipran. Neuropsychiatr Dis Treat. 2014;7(suppl 1):21-27.

17. Keller M. Role of serotonin and noradrenaline in social dysfunction: a review of data on reboxetine and the Social Adaptation Self-evaluation Scale (SASS). Gen Hosp Psychiatry. 2001;23(1):15-19.

18. McKnight PE, Kashdan TB. The importance of functional impairment to mental health outcomes: a case for reassessing our goals in depression treatment research. Clin Psychol Rev. 2009;29(3):243-259.

19. Sheehan KH, Sheehan DV. Assessing treatment effects in clinical trials with the discan metric of the Sheehan Disability Scale. Int Clin Psychopharmacol. 2008;23(2):70-83.

20. Thase ME. The small specific effects of antidepressants in clinical trials: what do they mean to psychiatrists? Curr Psychiatry Rep. 2011;13(6): 476-482.

21. Shiovitz T, Greenberg WM, Chen C, Forero G, Gommoll CPA. Randomized, double-blind, placebo controlled trial of the efficacy and safety of levomilnacipran ER 40-120 mg/day for prevention of relapse in patients with major depressive disorder. Innov Clin Neurosci. 2014;11(1-2):10-22.

22. Mago R, Forero G, Greenberg WM, Gommoll C, Chen C. Safety and tolerability of levomilnacipran ER in major depressive disorder: results from an open-label, 48-week extension study. Clin Drug Investig. 2013;33(10):761-771.

23. Savella ${ }^{\circledR}$ (milnacipran) [package insert]. St Louis, MO: Forest Laboratories Inc.; 2013. Available from: http://www.savellahcp.com/ savella-dosage.aspx.

24. Montgomery S, Briley M. Milnacipran: recent findings in depression. Neuropsychiatr Dis Treat. 2010;6(suppl 1):1-2.

25. Nakagawa A, Watanabe N, Omori IM, et al. Efficacy and tolerability of milnacipran in the treatment of major depression in comparison with other antidepressants: a systematic review and meta-analysis. CNS Drugs. 2008;22(7):587-602.

26. FDA's policy statement for the development of new stereoisomeric drugs. Chirality. 1992;4(5):338-340.

27. Pompili M, Serafini G, Innamorati M, et al. Agomelatine, a novel intriguing antidepressant option enhancing neuroplasticity: a critical review. World J Biol Psychiatry. 2013;14(6):412-431.

28. Palmer EC, Binns LN, Carey H. Levomilnacipran: a new serotoninnorepinephrine reuptake inhibitor for the treatment of major depressive disorder. Ann Pharmacother. 2014;48(8):1030-1039.
Neuropsychiatric Disease and Treatment

\section{Publish your work in this journal}

Neuropsychiatric Disease and Treatment is an international, peerreviewed journal of clinical therapeutics and pharmacology focusing on concise rapid reporting of clinical or pre-clinical studies on a range of neuropsychiatric and neurological disorders. This journal is indexed on PubMed Central, the 'PsycINFO' database and CAS,

\section{Dovepress}

and is the official journal of The International Neuropsychiatric Association (INA). The manuscript management system is completely online and includes a very quick and fair peer-review system, which is all easy to use. Visit http://www.dovepress.com/testimonials.php to read real quotes from published authors. 